\title{
AS LEITURAS DA COMMEDIA DANTESCA
}

\author{
Fernanda Moro Cechinel \\ Universidade Federal de Santa Catarina
}

\begin{abstract}
Resumo: Quando uma obra literária é lançada, a editora que o faz e, propriamente, o autor que a escreve esperam que ela ganhe os devidos louros da crítica e, consequentemente, alcance os méritos junto ao público leitor, mas isso só mesmo o tempo poderá dizer. Para aquelas que atingem o sucesso, as nomeamos de cânones ou clássicos. E a Commedia de Dante Alighieri é um exemplo. Desde sua escrita, no século XIV, até hoje, a obra dantesca inspirou diversos escritores mundo afora. O presente trabalho pretende elencar algumas obras, em poesia, prosa e também no cinema, que surgiram a partir do poema italiano. Importante deixar claro que não pretendemos aqui esgotar as obras, pois acredita-se que, ao longo de sete séculos, haja uma lista extremamente extensa de publicações que tiveram como ponto de partida a Commedia. Como referencial teórico para este artigo, utilizar-se-á, principalmente, a obra de Italo Calvino e a de Gilles Deleuze e Félix Guattari, com a teoria dos rizomas.
\end{abstract}

Palavras-chave: Literatura. Commedia. Clássico. Rizoma.

Os clássicos são aqueles livros dos quais, em geral, se ouve dizer: "Estou relendo...” e nunca “Estou lendo...”. (Italo Calvino, 1981)

I poeti, soprattutto quelli grandi, non possono fare a meno di stabilire contatti e confronti con i versi di Dante (Rino Caputo, 2013)

\section{Introdução}

A literatura mundial, ao longo dos tempos, elegeu seus cânones, aqueles que, de acordo com Italo Calvino, em Por que ler os clássicos? (1993), mesmo sem ler a obra, sabese de qual se trata, e, uma dessas obras é a Commedia (1304-21), de Dante Alighieri (12651321). Na religião, cânone são as obras escritas fruto da inspiração divina. Já, na literatura, chama-se cânone aquelas obras que marcaram um período histórico, estilo literário ou cultura. Ao nos debruçarmos sobre essas duas definições, e, tendo como ponto de partida a obra dantesca, Dante (personagem) nos dá uma pista de como a obra foi escrita:

Como lá fui parar dizer não sei;

Tão tolhido de sono me encontrava,

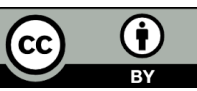

Esta obra está licenciada sob uma Creative Commons - Atribuição 4.0

\footnotetext{
* Bacharel em Turismo - Gestão Hotelaria pela Universidade do Sul de Santa Catarina -UNISUL (2010), Licenciada em Letras - Língua Italiana e Literaturas pela Universidade Federal de Santa Catarina - UFSC (2012) e Mestre em Literatura também pela UFSC (2015). E-mail: fernandamcechinel@yahoo.com.br.
} 
Dante (personagem) adormece e a narrativa discorre. Alguns podem dizer que a inspiração divina agiu por meio do sonho e a obra se deu. Tanto que, em determinado período da história, a Commedia foi utilizada como meio para catequização, ao revelar as punições sofridas por aqueles que "la diritta via era smarrita" (Inf. I: 12, p. 25, 2014). No entanto, atentemos nosso olhar para o significado literário de cânone. A Commedia transpôs a limitação de um período histórico ou literário: Dante marcou uma cultura, não só a italiana, mas toda uma cultura literária. No ocidente, não há como falarmos de literatura sem nos remetermos a essa obra. Tanto que até hoje, cerca de sete séculos após a sua escrita, ela continua sendo estudada, traduzida e sendo fonte de inspiração para outras obras, tal como veremos neste trabalho.

A expressão "nulla di nuovo sotto il sole", nos faz crer que tudo já foi escrito, tudo já foi dito. A diferença entre um texto e outro, então, é ‘como' foi escrito. E esse ‘como' é que torna cada obra uma história única. O tripé da literatura universal, sabe-se bem, é composto por amor, viagem e guerra. No amor, temos os grandes clássicos como Romeu e Julieta (1591-95), de Willian Shakespeare, até I Promessi Sposi (1840-42), de Alessandro Manzoni. $\mathrm{Na}$ viagem, além da Commedia, temos as Mil e uma noites (sec. IX ${ }^{1}$ ), Il Milione (1300), de Marco Polo, e a Odisséia (sec. VIII a. C.), de Homero. Já, na guerra, a Ilíada (sec. VIII a. C.), de Homero, O Diário de Anne Frank (1947), e tantas outras obras. O que se sabe também é que tudo aquilo que está sendo escrito, possivelmente, foi influenciado por leituras anteriores. Muitas vezes, não se sabe ao certo de quem é aquilo que se escreve, no entanto, sabe-se que aquilo já fora dito, e essa memória é conhecida como memória poética.

Os livros que marcaram a produção literária, além de cânones, também podem ser denominados de clássicos, e, para falarmos de clássico, retomemos Italo Calvino. Em sua obra Por que ler os clássicos? tem-se que o termo está relacionado à literatura grega ou latina, a obra ou autor de estilo impecável, constituindo modelo digno de imitação ou, simplesmente, antigo. No entanto, o próprio escritor questiona se clássicos são somente aqueles pertencentes à literatura grega ou latina. Se fosse assim, o que seria de Romeu e Julieta, de Shakespeare?

Por outro lado, dizer que clássicos são aqueles escritos ditos antigos, seria considerar que, na atualidade, não poderia existir clássicos. No entanto, Calvino mostra que tal definição é válida tanto para obras antigas quanto para modernas, ressaltando que cabe ao leitor saber colocar essas obras no local correto da "genealogia clássica".

\footnotetext{
${ }^{1}$ As histórias que compõem as Mil e uma noites vêm da tradição oral, sendo compiladas a partir do século IV, no Oriente.
} 
Ao definirmos clássico como obras dignas de imitação, novamente não há como não nos reportamos à Commedia, pois quantas outras obras surgiram a partir dela? Gilles Deleuze e Félix Guattari, na Introdução e Capítulo I, da obra Mil Platôs, volume 1 (1995), apresentam uma outra noção de literatura, muito diferente daquela que conhecemos.

Quando se pensa em literatura, para melhor entendimento e compreensão, busca-se sempre dividi-la, classificá-la em escolas, em gêneros, no entanto, Deleuze e Guattari propõem a troca dessa visão hierarquizada, para uma visão rizomática. A literatura pensada como rizoma, ou seja, um tronco como centro, que irradia raízes para várias direções, significaria que umas raízes, as mais fortes, sobreviveriam e se subdividiriam em outras raízes. Já outras, mais fracas, não perdurariam. É de extrema importância, então, para seguir nosso caminho, entender a Commedia como um rizoma, o tronco central. Mas qual seriam suas raízes? As raízes, que se criaram a partir desse tronco fecundo, são as tantas releituras da obra de Dante, aquelas feitas por Dan Brown, Marco Lucchesi, Sylvain Reynard... São essas as raízes que fazem com que as obras sobrevivam.

Eis que Deleuze e Guattari acrescentam também que literatura não tem ideologia e, partindo dessa afirmação, eis que surgem as seguintes perguntas: Quem é o sujeito da Commedia hoje? O fator ideológico para nós ainda é aquele da Commedia de outrora? Como a Commedia é tratada hoje? Que ideologia se usa para lê-la na atualidade? Perguntas essas, por ora sem resposta, mas que, no decorrer deste texto, procuraremos começar a esboçar. É sabido, como já dito anteriormente, que, por um longo período, a Commedia foi utilizada como instrumento de catequização da Igreja Católica, uma vez que mostrava, aos catequizados, os percursos que se pode percorrer em morte, devido às ações praticadas em vida. Possivelmente, temos aqui a primeira possibilidade de resposta para as perguntas apresentadas acima: a ideologia que se queria transmitir outrora, com o poema dantesco, não é a mesma a partir da qual pretendemos estudá-la hoje.

Neste trabalho, pretende-se apresentar um panorama parcial dos rizomas resultantes da Commedia, apropriando-nos da teoria de Deleuze e Guattari. Os materiais aqui apresentados seguirão duas vertentes: de um lado os filmes e de outro as produções literárias. Nas produções literárias também serão apresentadas as referentes à literatura brasileira. Ressaltamos novamente que não se pretende aqui esgotar esses rizomas, que, em se tratando da obra fundadora da literatura italiana, são inúmeros. 


\section{A Commedia e seus rizomas}

Dante foi escritor, poeta, político e apaixonado pela sua Itália e por Beatriz. O escritor italiano viveu num período tenso da Itália, entre os séculos XIII e XIV, durante os quais, facções políticas opostas, umas apoiadas pela Igreja e outras pelo imperador, disputavam o território italiano. E Dante não ficou longe desses acontecimentos, participou ativamente da vida política de Florença, sua cidade natal. Sua participação foi de tal forma que, por consequência dela, foi exilado e obrigado a deixar Florença, vivendo 18 anos se transferindo de cidade em cidade, até se fixar em Ravenna, onde faleceu em 1321.

É sabido que, ao longo de sua vida, o poeta escreveu algumas outras obras, no entanto, a Commedia - poema da viagem de Dante (personagem) pelo Inferno e Purgatório, guiado pelo poeta Virgílio, e, pelo Paraíso, onde encontra sua amada Beatriz - se destaca entre as demais, tanto que recebeu a alcunha de Divina, provavelmente de Giovanni Boccaccio.

Desde a infância, seguindo a tradição da época, Dante estudou pensadores como Cícero e Virgílio, tendo contato com inúmeras obras, bem como com o pensamento de diversos estudiosos de outras ciências. Na idade adulta, estudou filosofia, teologia e os poetas clássicos. Estudou também as obras cristãs, de Santo Agostinho e São Tomás de Aquino, e de autores clássicos, entre eles Boécio, Aristóteles, Ovídio e Lucano. E, como seria de se esperar, aquilo que Dante viveu e, principalmente, leu, durante sua vida, influenciou suas obras. Estas são suas palavras ditas a Virgílio:

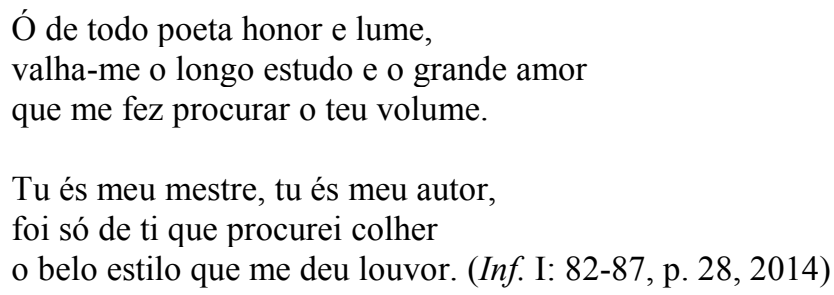

Assim como Dante buscou diversos autores para lhe darem subsídios na escrita de sua Commedia, vários escritores se utilizaram dessa árvore fecunda para alcançarem sua glória. Iniciemos aqui, então, a apresentar um pequeno panorama desses que utilizaram, como ponto de partida, a obra dantesca.

Alguns anos depois da publicação da Commedia, quando Dante já estava morto, Giovanni Boccaccio resolveu dar o destaque e a divulgação que o texto merecia, tanto que iniciou sua Esposizione sopra la Commedia (1379), ou seja, eram leituras feitas em público da obra de Dante. O fato de se reproduzir de forma oral a Commedia é conhecida, 
principalmente, no sul da Itália, como Dante a mente. No entanto, essas foram interrompidas pela doença que acometeu Boccaccio. Dando um grande salto pelos séculos sucessivos, temse, no século XX, as transmissões radiofônicas, feitas por Vittorio Sermonti, com a leitura da Commedia, duraram 10 anos, sendo seguida por Vittorio Gassmann, que atentou-se à leitura de alguns cantos.

A obra dantesca também se destacou em outro campo, a sétima arte. No cinema, a Commedia inspirou o primeiro filme italiano, ainda mudo, lançado em 1911, L'Inferno, de Giuseppe de Liguoro. O filme narra o percurso de Dante (personagem) pelos três mundos. Para isso, utilizou-se dos subsídios mais tecnológicos disponíveis à época, sendo considerada, no período, uma superprodução. Os cenários basearam-se nas ilustrações de Gustave Doré, outra adaptação à parte da obra dantesca.

Imagem 01: Cena do filme L'Inferno (1911)

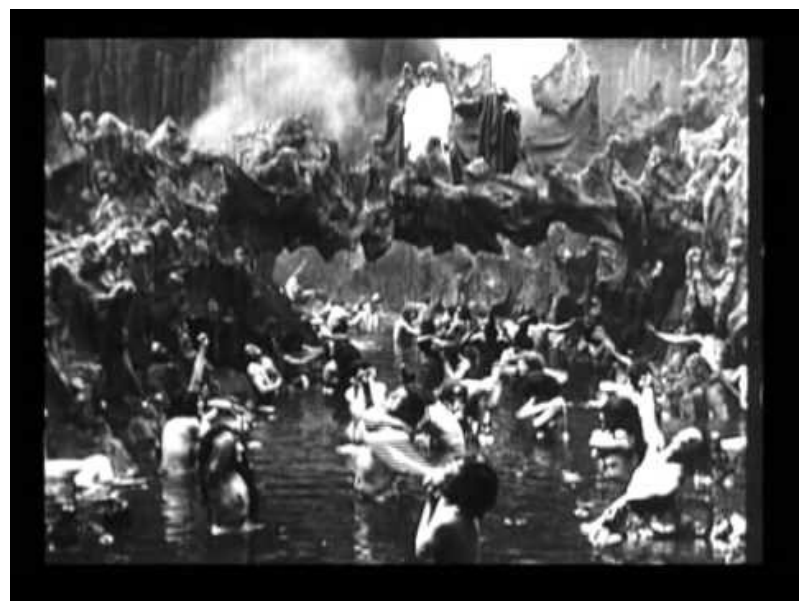

Fonte: Youtube (2014)

Se, supostamente, Boccaccio alcunhou de Divina a Commedia dantesca, e hoje é impossível dissociá-la de seu nome original, com as ilustrações de Gustave Doré temos a mesma sensação. Apresentadas pela primeira vez em 1861, em uma edição francesa do Inferno, tendo alguns anos depois Gustave Doré feito as do Purgatório e Paraíso, as ilustrações hoje acompanham e auxiliam os leitores do mundo inteiro na leitura do poema dantesco 


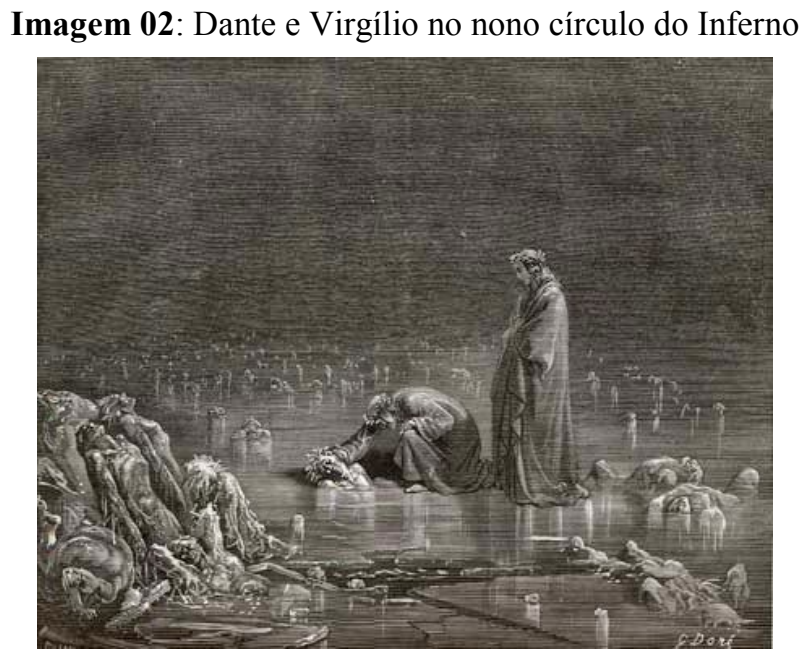

Fonte: Wikiwand (2014)

Retomando os filmes inspirados na Commedia, temos, em 1924, Dante's Inferno, de Henry Otto. Ainda no início de sua obra, após passar pela entrada do primeiro círculo infernal, eis que Dante e Virgílio chegam ao segundo círculo, destinado àqueles que cometeram o pecado da luxúria, e lá também encontramos Francesca, narrando sua história e de Paolo.

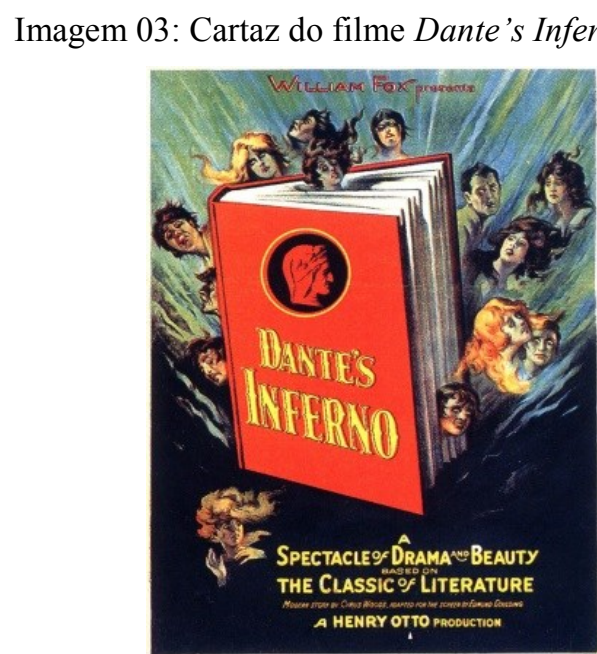

Fonte: Wikipedia (2017)

A história de Paolo e Francesca, além de narrada por Dante, também apareceu, séculos mais tarde após o surgimento da obra, no filme The Drum of Love (1935), de Griffiths. Na sequência de filmes que se inspiram na poesia de Dante, tem-se: Seven (1995), de David Fincher; Silêncio dos Inocentes (1991), de Jonathan Demme; Amor além da vida (1998), de Vicent Ward; O Reflexo do Medo (2014), de John Erick Dowdle... Em 2013, alguns rumores ainda não concretizados, anunciaram que Roberto Benigni, mundialmente conhecido após o sucesso de $A$ vida é bela (1997), faria um filme baseado na Commedia.

Dante, além dos diretores e roteiristas de cinema, também inspirou escritores, sendo 
Alessandro Manzoni um deles. Sua inspiração aparece no Canto III do Paraíso, o qual conta a história da freira que foi raptada, Piccarda Donati, e que se encontra no primeiro círculo do céu, a Lua, local para aqueles que não conseguem seguir seus votos religiosos, pois foram impedidos de fazê-lo, mas que também, ao terem a oportunidade de voltar à vida religiosa, não o fizeram.

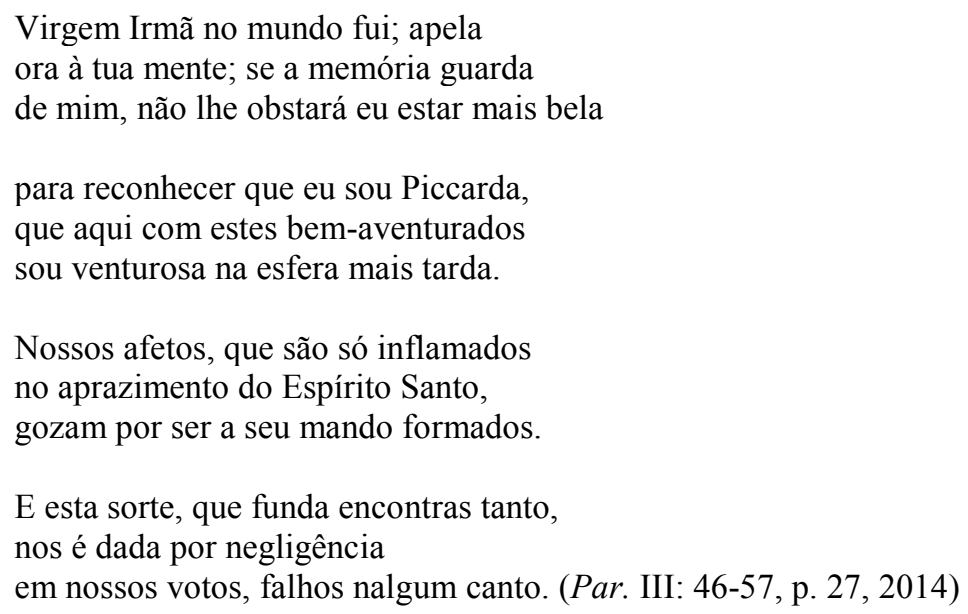

Séculos mais tarde, em I Promessi Sposi (1840-42), Manzoni se inspira na história de Piccarda, mas, utilizando como personagem Lúcia. Ignazio Silone que, por sua vez, foi leitor de Manzoni, também criou uma noviça em suas obras, Severina (2011). Severina, devido as suas opiniões contrárias àquelas da Igreja, representada pela Madre Superiora, viu-se obrigada a deixar o convento e a vida religiosa. Outro, que pode ter se inspirado em Dante, foi Carlo Goldoni, que "criou" o personagem Arlequim, na peça Arlequim, servidor de dois amos (1976), já que Dante, no Canto XXI do Inferno, fala daqueles que trapacearam na conquista de cargos públicos ou que roubaram seus patrões.

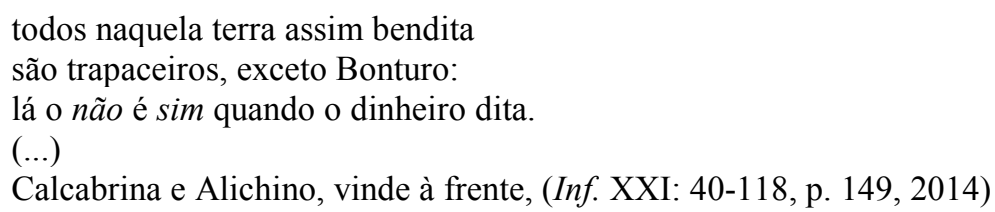

Seguindo na esteira de Manzoni (1840-42), temos, ainda como obras que fizeram referências à Commedia, Nove ensaios dantescos (2011), do argentino Jorge Luis Borges, texto escrito entre as décadas de 40 e 50. Borges (1899-1986), tido como escritor de periferia, influenciou escritores consagrados, como Italo Calvino e Umberto Eco. A primeira obra do escritor argentino sobre Dante foi Mi primer encuentro con Dante (1961), na qual ele narra seu primeiro contato com a Commedia, que foi em um trem. Nesse trem, o escritor argentino começou a leitura, na tradução para o inglês, e a concluiu em italiano. 
Apresentam-se também, como rizomas da Commedia, Paraiso Perduto (2015), de John Milton; a poesia Invernale, constante na obra I Colloqui (1911), de Guido Gozzano; Se questo è un uomo (1947), de Primo Levi; O Clube Dante (2005), de Matthew Pearl; a trilogia Os crimes do Mosaico (2006), Os crimes da Medusa (2006) e Os crimes da Luz (2007), de Giulio Leoni; Todos contra Dante (2008), de Luís Dill; A Armadilha de Dante (2010), de Arnaud Delalande; o capítulo Infernos, que aparece na obra Sobrevivência dos vagalumes (2011), de Georges Didi Huberman; Aristóteles e Dante Descobrem Os Segredos do Universo (2012), de Benjamin Alire Sáenz; Inferno (2014), de Dan Brown - também adaptado para o cinema -; Il mistero del male (2013), de Giorgio Agamben; a trilogia O inferno de Gabriel (2013) O julgamento de Gabriel (2013) e A redenção de Gabriel (2014), de Sylvain Reynard; Condenada (2013) e Maldita (2014), de Chuck Palahniuk.

\section{A Commedia no Brasil}

Em específico no Brasil, também há publicações que se inspiraram na obra de Dante: Nel mezzo del camin, de Olavo Bilac; No meio do caminho (1930) e A máquina do mundo, publicadas em Claro Enigma (1951), de Carlos Drummond de Andrade; Prefácio Interessantíssimo, de Paulicéia Desvairada (1922), a poesia Carnaval Carioca, da obra Clã do Jabuti (1927) e Macunaíma (1928), de Mario de Andrade; Invenção de Orfeu (1952), de Jorge de Lima; Tambor cósmico e Constelações, de César Leal; Meu Dante (1969), de Henriqueta Lisboa; Finismundo: a última viagem (1990), de Haroldo de Campos; Por que ler Dante, de Eduardo Sterzi (2008); A Divina Paródia (2009), de Álvaro Cardoso Gomes; e Nove cartas sobre A divina comédia - Navegações pela obra clássica de Dante (2013), de Marco Lucchesi.

Dentre as raízes oriundas da Commedia, aqui no Brasil, um escritor ganhou destaque por sua proximidade com Dante, originando a pesquisa de diversos estudiosos da área literária: Machado de Assis, denominado por alguns como "O Dante do Cosme Velho", em sua obra Memórias póstumas de Brás Cubas (2009), na qual há o capítulo Virgília casada. A obra apresenta semelhanças com a dantesca, já na composição de seus personagens, uma vez que a obra machadiana é narrada pela perspectiva de um morto, Brás Cubas, cuja amada chama-se Virgília. Machado também citou trechos da Commedia em outros textos, como Aurora sem dia (1873) e A nova geração (1879). 


\section{Conclusão}

As perguntas lançadas originalmente, após a introdução feita a partir de Deleuze e Guattari, sobre entender a literatura não como um sistema classificatório e linear, no qual, cada texto deve pertencer a uma determinada etiqueta e sem ponto de contato com as demais obras, mas sim, um sistema rizomático, no qual há um tronco principal e fecundo que proporciona o surgimento de diversas raízes, umas mais fortes, que se fixam ao longo do caminho e sobrevivem, outras, mais fracas, apenas surgem e após definham, nos faz pensar que é assim que devemos entender a literatura. Nesse sentido, a Commedia foi um dos troncos centrais do qual se originaram diversas raízes. Algumas, logo em princípio, já se apresentaram como raízes fortes, caso de Agamben, outras só o tempo dirá se sobreviverão. Mas, retornemos aos nossos questionamentos: Quem é o sujeito da Commedia hoje? O fator ideológico para nós ainda é aquele da Commedia de outrora? Como a Commedia é tratada hoje? Que ideologia se usa para isso?

A Commedia fora dita como o grande poema universal, segundo Borges. Para outros, como poema sacro e, ao longo de seus versos, nos trouxe uma Itália de disputas entre guelfos e gibelinos, de amores proibidos, como o de Paolo e Francesca, de histórias interrompidas, como a de Piccarda Donati, da corrupção da Igreja, levando papas ao total desprestígio, sendo postos no Inferno - um deles devido à sua renúncia como verdadeiro apóstolo de Cristo, outros tantos devido às suas más conduções da Igreja Cristã. Pode-se concluir que a Commedia, independente da sua época, é a história do homem, da humanidade, santa e pecadora que, ao longo de sua existência terrena, vive sobre a balança do bem e do mal, mas que, após a morte, do lado de lá, almeja, independente de suas atitudes na terra, quando vivos, alcançar o Empíreo.

E, nesse fato, reside a contemporaneidade, nos moldes cunhados por Giorgio Agamben, da obra dantesca. Em O que é o contemporâneo? (2009) Agamben sugere trazer os textos, independente da época que foram escritos, para analisarmos sobre a ótica do hoje, e esse anacronismo é chamado de contemporâneo. Contemporâneo é o fato de uma obra ter sido escrita há sete séculos, mas ainda continuar tão presente, despertando cada vez mais a leitura de diversos estudiosos, seja no campo da filosofia, seja por meio das religiões, seja na literatura. Não ao acaso, a Commedia é a mãe de uma língua, já que essa obra suscita estudos desde seu título, perpassando pela sua formatação física, a questão linguística, histórica...

Retomando, então, o conceito de Calvino sobre os clássicos, verifica-se que não se possui um conceito fechado, restrito, do que esses clássicos realmente são, tornando-se uma 
verdade universal. O quê há são constatações que ajudam a identificá-los. Os clássicos não são lançados como clássicos, é a sociedade que os transforma em clássicos, pois é ela a responsável em fazer com que um dado livro esteja vivo por várias gerações, influenciando pensamentos e culturas. São as releituras e também as traduções da Commedia que fazem com que ela ultrapasse as fronteiras físicas e também da história.

A riqueza da Commedia está na sua inesgotabilidade, pelo menos até onde conseguimos vislumbrar, de seus estudos. O grande poema de Dante sempre foi visto, por aqueles que, assim como nós, estão começando a trilhar os caminhos da literatura, como o texto reservado aos sábios, tal como o livro proibido pelo bibliotecário, em $O$ nome da rosa (2009), de Umberto Eco. No entanto, este livro de difícil acesso, já que estava colocado na prateleira, muito distante de nosso alcance, foi retirado e trazido até nós. E, diante dele, nos perguntamos: conseguiremos compreender toda a sua magnitude? Com certeza não, pois a Commedia é fonte inesgotável de saber. A certeza que temos é que, com os recursos certos, começamos a compreendê-la, e que a viagem pela selva escura tornou-se mais clara com a ajuda dos vagalumes, como apresentado por Pier Paolo Pasolini (1975) que, tal como a obra dantesca, perduram até os dias atuais, mesmo em meio a tantas adversidades.

\section{Referências}

AGAMBEN, Giorgio. Il mistero del male. Roma: Editori Laterza, 2013.

. O que é contemporâneo e outros ensaios. Trad. de Vinícius Nicastro Honesko. Chapecó: Argos. 2009.

ALIGHIERI, Dante. A Divina Comédia. Trad. de Italo Eugenio Mauro. São Paulo: Editora 34, 2014.

ASSIS, Machado de. Memórias póstumas de Brás Cubas. São Paulo: Saraiva, 2009.

BORGES, Jorge Luis. Nove ensaios dantescos \& a memória de Shakespeare. Trad. de Heloisa Jahn. São Paulo: Companhia das Letras, 2011.

BROWN, Dan. Inferno. São Paulo: Arqueiro, 2013.

CALVINO, Italo. Por que ler os clássicos? Trad. de N. Moulin. São Paulo: Companhia das Letras, 1993.

DELEUZE, Gilles; GUATTARI, Félix. Mil Platôs. v. 1. São Paulo: Editora 34, 1995.

DELLANDE, Arnaud. A Armadilha de Dante. Rio de Janeiro: Record, 2009.

DILL, Luís. Todos contra Dante. São Paulo: Companhia das Letras, 2008. 
GOLDONI, Carlo. Arlequim, servidor de dois amos. Trad. de Elvira Rina Malerbi Ricci. São Paulo: Abril, 1976.

GOZZANO, Guido. I Colloqui. FTE: Milão, 1911.

HUBERMAN, Georges Didi. Sobrevivência dos vagalumes. Trad. de Márcia Arbex e Vera Casa Nova. Belo Horizonte: EdUFMG, 2011.

LEONI, Giulio. Os crimes da Luz. Trad. de Gian Bruno Grosso. São Paulo: Planeta, 2007. . Os crimes da Medusa. Trad. de Gian Bruno Grosso. São Paulo: Planeta, 2006. . Os crimes do Mosaico. Trad. de Gian Bruno Grosso.São Paulo: Planeta, 2006.

LEVI, Primo. Se questo è un uomo. Turim: De Silva, 1947.

MANZONI, Alessandro. Os noivos. São Paulo: Paulinas, 1959.

MILTON, John. Paraíso Perdido. Trad. de Daniel Jonas. São Paulo: Editora 34, 2015.

PALAHNIUK, Chuck. Condenada. Rio de Janeiro: Leya, 2014. . Maldita. Rio de Janeiro: Casa da Palavra, 2014.

PASOLINI, Pier Paulo. Il vuoto del potere. Corriere della Sera, 1 fev. 1975.

PEARL, Matthew. O Clube Dante. Trad. de Maria José Silveira. São Paulo: Francis, 2005.

REYNARD, Sylvain. A redenção de Gabriel. Trad. de Fabiano Morais. São Paulo: Arqueiro, 2014.

. O inferno de Gabriel. Trad. de Fabiano Morais. São Paulo: Arqueiro, 2013.

. O julgamento de Gabriel. Trad. de Fabiano Morais. São Paulo: Arqueiro, 2013.

SÁENZ, Benjamim Alire. Aristóteles e Dante Descobrem Os Segredos do Universo. Trad. de Clemente Pereira. São Paulo: Seguinte, 2014.

SILONE, Ignazio. Severina. Milão: Mondadori, 2011.

UMBERTO, Eco. O nome da rosa. Trad. de Aurora Fornoni Bernardini e Homero Freitas de Andrade. Rio de Janeiro: Record, 2009.

\section{Créditos das imagens}

Imagem 01: https://www.youtube.com/watch?v=3M9e6jxA9tA

Imagem 02: http://www.wikiwand.com/pt/Inferno_(Divina_Com\%C3\%A9dia)

Imagem 03: https://en.wikipedia.org/wiki/Dante\%27s_Inferno_(1924_film) 


\section{The readings of the dantesque Commedia}

Abstract: When a literary work is published, the publisher who does it and, properly, the author who writes it, expects it to be well criticized and, consequently, to achieve the merits within the readers, but that only time can tell. Those that achieve success are called canons or classics. Dante Alighieri's Commedia is an example. Since his writing, in the fourteenth century, to this day, the Dantesque work has inspired many writers worldwide. The present work intends to list some works, in poetry, prose and in the cinema, which originated from the Italian poem. It is important to highlight that we do not intend to discuss all the works here, since it is believed that over seven centuries there is an extremely extensive list of publications that had Commedia as starting point. As a theoretical reference for this article, the work of Italo Calvino and Gilles Deleuze and Félix Guattari, with the rhizomes theory, will be used.

Keywords: Literature. Commedia. Classic. Rhizome.

Recebido em: 29/09/2017

Aceito em: 04/10/2017

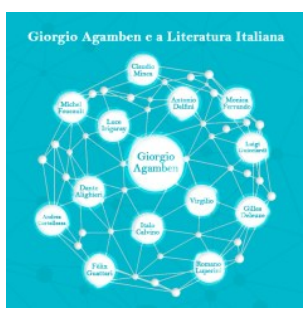

